\title{
Tipologia dos estabelecimentos escolares brasileiros
}

\author{
Cezar Augusto Cerqueira* \\ Diana Reiko Oya Tutya Sawyer ${ }^{* *}$
}

\begin{abstract}
A proposta central do trabalho é a construção de uma tipologia para os estabelecimentos escolares brasileiros, a partir de um amplo conjunto de informações que envolvem a infra-estrutura oferecida pelos mesmos, seu porte, indicadores de qualidade do ensino oferecido, entre outros aspectos. A construção da tipologia cristaliza-se no delineamento de perfis extremos de escolas, na verdade grupos com características marcantes. Uma outra dimensão investigada foi a eficácia escolar, tendo como principal interesse verificar sua distribuição segundo os perfis anteriormente gerados. A tipologia das escolas revelou três perfis extremos: um de escolas com precárias condições de infraestrutura e indicadores deficientes de eficácia escolar; outro, em situação oposta, com grandes escolas, com boas condições de infra-estrutura e bons indicadores de eficácia; e um terceiro perfil, que ficou em uma posição de transição entre os dois primeiros. Preocupa o fato de que a maioria das escolas brasileiras aderiu ao perfil de precárias condições de infra-estrutura, quadro agravado pelas disparidades regionais.
\end{abstract}

Palavras-chave: Educação. Demografia da educação. Escolas.

\section{Introdução}

O cenário delineado, nas últimas décadas, para o sistema educacional brasileiro, revela importantes transformações em seus diversos aspectos, com destaque para a ampliação do acesso à escola no ensino fundamental, além de uma melhoria nos níveis médios de escolarização atingidos. Entretanto, o Brasil ainda não alcançou patamares satisfatórios, situando-se em posição inferior a diversos países em desenvolvimento, tais como Colômbia, Bolívia e Equador, entre outros. Uma questão que também merece destaque diz respeito às desigualdades, principalmente regionais, em termos de acesso a oportunidades educacionais (MARTELETO, 2000).
Do ponto de vista demográfico, também foram observadas profundas mudanças no país, nas últimas décadas, destacando-se a redução no ritmo das taxas de crescimento populacional, conseqüência dos novos cenários delineados pela transição demográfica brasileira, em especial a partir dos anos 70, resultado, principalmente, da queda nos níveis de fecundidade. Tais mudanças têm provocado decréscimo na proporção de população em idade de cursar a educação primária, de tal modo que a falta de escolas parece não ser o principal problema do sistema brasileiro de educação, devendo ser dada maior atenção a questões como qualidade da educação e repetência (FLETCHER; RIBEIRO, 1987; KLEIN; RIBEIRO, 1991). Assim, assume

\footnotetext{
*Professor Doutor da Universidade Católica de Pernambuco - Unicap e Universidade de Pernambuco - UPE.

${ }^{* *}$ Professora Phd do Centro de Desenvolvimento e Planejamento Regional - Cedeplar, da Universidade Federal de Minas Gerais -UFMG.
} 
crucial importância a investigação de aspectos sobre qualidade, eficácia e rendimento escolar.

Já a importância atribuída aos recursos escolares, entendidos como instalações e equipamentos existentes, que emerge da literatura sobre o desempenho escolar nos países em desenvolvimento, ressalta a urgente necessidade de que se aprofunde o conhecimento a respeito da realidade dos estabelecimentos escolares brasileiros, principalmente sobre como ocorre a distribuição dos recursos escolares, dada a premissa de que os resultados escolares, especialmente em países em desenvolvimento, são sensíveis aos níveis de recursos escolares (BUCHMAN; HANNUM, 2001).

A proposta central deste trabalho é construir uma tipologia dos estabelecimentos escolares brasileiros, definindo seus perfis, com base em um amplo conjunto de indicadores que procuram retratar aspectos ligados a infra-estrutura, porte e características funcionais das escolas, além de indicadores do nível socioeconômico dos municípios onde as mesmas estão localizadas.

\section{Aspectos metodológicos}

As variáveis utilizadas na caracterização dos estabelecimentos escolares e construção da tipologia foram classificadas em três dimensões: i) aspectos da comunidade, em que se busca caracterizar os fatores ligados aos contextos social, espacial e demográfico da área onde a escola está localizada; ii) infra-estrutura existente na escola, em que se pretende traduzir o potencial de cada estabelecimento escolar, em termos dos recursos e instalações disponíveis, o que, pelo anteriormente discutido, tem grande importância nos resultados escolares alcançados, principalmente em países em desenvolvimento; iii) características funcionais das escolas, incluindo-se indicadores do porte, disponibilidade e qualificação dos docentes, tamanho de classe, horas-aula diárias, entre outros, que sabidamente têm acentuada importância no processo de ensino/aprendizagem.
Os caminhos metodológicos seguidos no desenvolvimento do trabalho podem ser visualizados em três grandes etapas. A primeira trata da construção de uma tipologia municipal, que procura fornecer informações sintéticas sobre o ambiente onde cada escola está inserida. A segunda e principal etapa aborda a elaboração da tipologia dos estabelecimentos educacionais, a partir de um amplo conjunto de indicadores relativos a diversos aspectos das escolas. A terceira consiste em verificar possíveis associações, considerando-se, de um lado, um conjunto de variáveis chamadas de externas, que procuram caracterizar aspectos relacionados com a eficácia educacional, e, de outro, os perfis estruturais e funcionais anteriormente construídos. Todas essas etapas são desenvolvidas com o apoio do método Grade of Membership - GoM (MANTON et al., 1994), que lida com dois dos maiores problemas na determinação de uma classificação ou tipologia, que são a identificação de grupos e a descrição de diferenças entre os mesmos.

Uma clara vantagem do método é não necessariamente assumir que os grupos são fixos, além de apresentar propriedades extremamente importantes para o problema em questão. A primeira é permitir que os estabelecimentos escolares possam pertencer a mais de um grupo ou perfil, possibilitando que a heterogeneidade entre os mesmos seja expressa como um componente do modelo, o que leva a descrições mais naturais dos grupos a serem gerados. Uma outra vantagem é a possibilidade de lidar com grande número de casos e variáveis. O método é baseado em procedimentos de estimação estatística de máxima verossimilhança, tendo, portanto, o rigor estatístico necessário para atender aos objetivos desse estudo.

A aplicação do método GoM requer dados de $\mathrm{J}$ variáveis-resposta discretas, com um número finito $(L j)$ de categorias de respostas para a j-ésima variável. Para variáveis de natureza intrinsecamente discreta (sexo, região, etc.), a codificação é direta. Neste caso, os dados podem ser vistos como consistindo de $\mathrm{J}$ variáveis multinomiais $\left(X_{i j}\right)$ com $L_{j}$ níveis de resposta 
para a j-ésima variável, ou, de forma equivalente, definir $\mathrm{Y}_{\mathrm{ijl}}$ como a resposta do indivíduo i à categoria $\mathrm{I}$, da variável $\mathrm{j}$, sendo uma variável binária, ou seja, assumindo valor 1 se este pertence à l-ésima categoria ou 0 , caso contrário. Para cada escola é estimado um escore de pertinência, ou escore GoM, denotado por $\mathrm{g}_{\mathrm{ik}}$, o qual indica o grau de pertinência do i-ésimo elemento, ao k-ésimo conjunto ou perfil. Tais escores variam no intervalo $[0,1]$; um escore 0 (zero) indica que o estabelecimento escolar não pertence ao perfil K, enquanto um escore 1 (hum) significa que este possui todas as características do k-ésimo perfil.

A probabilidade da resposta I, para a jésima variável, pela escola com k-ésimo perfil extremo é denotada por $\lambda_{\mathrm{kj} \neq \mathrm{t}}$. Por pressuposto do modelo, existe pelo menos uma unidade que é membro bem definido do késimo perfil. Este pressuposto dá a probabilidade de resposta, para esta unidade, para os vários níveis de cada variável. Os $\lambda_{\mathrm{kjl}}$ são valores positivos, cuja soma é igual a um, para os níveis de cada variável, dentro de cada perfil.

Complementado por uma série de outros pressupostos (MANTON et al., 1994), o modelo de probabilidade para a construção do procedimento de estimação de máxima verossimilhança é formulado. Os parâmetros de interesse são então estimados a partir da maximização da expressão:

$$
L(Y)=\prod_{i=1}^{l} \prod_{j=1}^{J} \prod_{l=1}^{L_{j}}\left(\sum_{k=1}^{K} g_{i k} \lambda_{k j l}\right)^{y_{i j l}}
$$

\section{Resultados}

\section{Os perfis extremos}

A construção da tipologia dos estabelecimentos escolares pode ser visualizada em duas grandes etapas, que são a construção dos perfis extremos e o cálculo dos escores de pertencimento dos estabelecimentos escolares a cada perfil gerado. As características de cada perfil são delineadas de acordo com o exame dos valores dos $\lambda_{\mathrm{kj}}$ - fornecidos pelo método GoM - e, posteriormente, comparados com a freqüência marginal correspondente. Optou- se pela definição de três perfis extremos, com resultados bastante satisfatórios, atendendo a princípios de parcimônia e facilidade de interpretação. A condição para caracterizar os perfis considerou como regra de decisão se a estimativa dos $\lambda_{\mathrm{kj}}$ fosse suficientemente maior que a respectiva freqüência marginal. Foi definido o valor de 1,2 para a razão entre os $I_{k j l}$ e as freqüências marginais correspondentes, ou seja, os valores que delineiam as características predominantes em cada perfil correspondem à situação em que as probabilidades $\lambda_{\text {kjl }}$ estimadas excedem em mais de $20 \%$ a sua freqüência marginal na população. $A$ seguir são apresentadas as características de cada um dos três perfis extremos delineados.

O perfil extremo 1 é formado por escolas com as seguintes características: localizadas em municípios das Regiões Norte e Nordeste; em geral de baixo e médio-baixo potencial humano e produtivo, em área rural; pertencentes à rede municipal; desprovidas de instalações escolares tais como biblioteca, cozinha, quadra, sala de TV-vídeo; não ligadas à rede de esgoto; desprovidas ainda de equipamentos de comunicação (TV, vídeo e parabólica) e de equipamentos de informática. Em termos de porte, tais escolas funcionam com um ou dois professores, apenas uma sala de aula, poucas turmas no fundamental e até 30 alunos. Oferecem ainda quatro horas-aula diárias no ensino fundamental, observandose que em sua totalidade tais escolas não contavam com nenhum professor com curso superior completo, em 2000. No tocante ao nível de ensino ofertado, os resultados sugerem presença de escolas que não oferecem o ensino médio, incluindo ainda aquelas de nível pré-escolar. De acordo com os fatores predominantes nesse perfil, suas características mais marcantes podem ser resumidas como: pequenas escolas, de ensino fundamental, sem infra-estrutura, rurais, municipais, não informatizadas, com baixíssima qualificação docente, doravante referidas como escolas de baixa infraestrutura.

O perfil extremo 2 corresponde aos seguintes tipos de escola: localizadas em 
municípios com características da Região Sul, de médio a elevado potencial humano e produtivo, em áreas urbanas; pertencentes às redes estadual ou privada; com instalações tais como biblioteca, sala de professores, refeitório, sala de TV e vídeo, indicando a presença de equipamentos de comunicação (TV, vídeo e antena parabólica). Em termos de recursos de informática, em geral tais escolas não têm acesso à Internet e dispõem de apenas um computador. Quanto ao porte, tal perfil sugere escolas que podem ter entre 3 e 16 professores, de 2 a 10 salas de aula, de 4 a 19 turmas no ensino fundamental, mais de $15 \%$ de alunos em período noturno no ensino fundamental e de baixo a médio/alto nível de qualificação docente. Tais escolas oferecem apenas o ensino fundamental. De acordo com as características predominantes, este perfil poderia ser classificado como de escolas de porte médio, de ensino fundamental, com razoável nível de infraestrutura, urbanas, estaduais ou particulares, não informatizadas, com médio/alto nível de qualificação docente, doravante chamadas de escolas de média infraestrutura.

O perfil extremo 3 é formado por escolas com as seguintes características: localizadas em municípios das Regiões Sul, Sudeste ou Centro-Oeste, de alto potencial humano e produtivo, em áreas urbanas; pertencentes às redes estadual ou privada; com instalações tais como biblioteca, videoteca, quadra, laboratório de ciências, sala de TV e vídeo, indicando a presença de equipamentos básicos de comunicação (TV, vídeo e antena parabólica); são escolas bastante informatizadas, com acesso à Internet, contando com rede local, laboratório de informática e impressora, o que indica a presença de um ou mais computadores. No tocante ao porte, esses estabelecimentos têm 17 ou mais professores, de 6 a mais de 20 salas de aula e dez ou mais turmas no ensino fundamental. São escolas de ensino fundamental de grande porte ou de ensino médio de pequeno ou grande porte, com, no máximo, $31 \%$ de alunos em período noturno no ensino fundamental, oferecem quatro ou mais de cinco horas diárias no ensino fundamental e apresentam de médios a muito elevados níveis de qualificação docente. No que tange ao tipo de ensino oferecido, são escolas com apenas o ensino médio ou ambos (fundamental e médio).

Um exame das características predominantes nesse perfil permite resumi-lo como de grandes escolas urbanas, de ensino médio e/ou fundamental, com elevado nível de infra-estrutura, estaduais ou particulares, com altos níveis de informatização e de qualificação docente, referidas como escolas de elevada infra-estrutura.

\section{Os perfis mistos}

A metodologia aplicada na construção da tipologia permite, conforme discutido anteriormente, que as escolas possam ser membros parciais dos diversos perfis extremos, o que torna necessário aprofundar a investigação dos mesmos. Desse modo, foram criadas expressões booleanas para possibilitar a criação de tipos mistos de perfis, a fim de se verificarem os perfis predominantes, que descrevessem a combinação de graus de pertinência dos estabelecimentos escolares. Os perfis predominantes (puros) e os mistos são descritos a seguir, exemplificando-se para o caso dos perfis 1 e 2 .

\section{- Predominância do perfil 1 (P1):}

Se $\left\{g_{1 k}>=0,75\right\}$; a escola tem pelo menos $75 \%$ das características do perfil extremo 1, ou ainda se:

$$
\left\{0,5=<g_{i 1}<0,75\right\} \cap\left\{g_{12}<0,25\right\} \cap\left\{g_{i 3}<0,25\right\}
$$

- Perfil misto com predominância (PM12):

\section{$\mathrm{Se}$}

$$
\left\{0,5=<\mathrm{g}_{11}<0,75\right\} \cap\left\{0,25=<\mathrm{g}_{2}<0,5\right\} \cap\left\{\mathrm{g}_{3}<0,25\right\}
$$

Foram considerados amorfos, ou sem definição, os estabelecimentos escolares cujos escores de pertinência aos três perfis foram inferiores a 0,50.

A Tabela 1 apresenta os perfis extremos e mistos encontrados e a freqüência absoluta e relativa, de escolas e matriculados, bem como uma descrição resumida de cada perfil extremo. 
TABELA 1

Distribuição das escolas e matrículas, segundo os perfis extremos e mistos construídos Brasil -2000

\begin{tabular}{|c|c|c|c|c|c|}
\hline \multirow{2}{*}{ Perfil } & \multirow{2}{*}{ Predominância } & \multicolumn{2}{|l|}{ Escolas } & \multicolumn{2}{|c|}{ Matrículas } \\
\hline & & $\mathbf{N}^{\circ s}$ Absolutos & $\%$ & $\mathrm{~N}^{\circ \mathrm{s}}$ Absolutos & $\%$ \\
\hline Perfil 1 & $\mathrm{P} 1$ & 106.871 & 49,2 & 2.961 .351 & 6,7 \\
\hline Pequenas escolas rurais municipais & PM12 & 16.790 & 7,7 & 940.646 & 2,1 \\
\hline \multirow[t]{2}{*}{ mal equipadas } & PM13 & 3.264 & 1,5 & 80.652 & 0,2 \\
\hline & Subtotal & 126.925 & 58,4 & 3.982 .649 & 9,1 \\
\hline Perfil 2 & $\mathrm{P} 2$ & 34.691 & 16,0 & 7.927 .895 & 18,1 \\
\hline Escolas de médio/grande porte, com & PM21 & 8.835 & 4,1 & 1.224 .443 & 2,8 \\
\hline equipamentos/instalações básicas, & PM23 & 10.072 & 4,6 & 4.862 .626 & 11,1 \\
\hline não informatizadas, ensino fundamental & Subtotal & 53.598 & 24,7 & 14.014 .964 & 31,9 \\
\hline Perfil 3 & P3 & 20.957 & 9,6 & 19.991 .685 & 45,5 \\
\hline Grandes escolas urbanas, bem equip., & PM31 & 3.485 & 1,6 & 482.580 & 1,1 \\
\hline com boas instalações, informatizadas, & PM32 & 7.499 & 3,4 & 4.878 .100 & 11,1 \\
\hline ensino fundamental & Subtotal & 31.941 & 14,7 & 25.352 .365 & 57,7 \\
\hline Não definidos & & 4.948 & 2,3 & 560.918 & 1,3 \\
\hline Total & & 217.412 & 100,0 & 43.910 .896 & 100,0 \\
\hline
\end{tabular}

Fonte: Instituto Nacional de Estudos e Pesquisas Educacionais Anísio Teixeira - Inep. .Elaboração própria.

A maioria dos estabelecimentos escolares do país aderiu ao perfil extremo 1 , de escolas pequenas, rurais, desprovidas de infra-estrutura - predominante em quase metade delas $(49,2 \%)$. Somando-se esse percentual com os perfis mistos com predominância, verifica-se que $58,4 \%$ das escolas classificam-se neste perfil, sendo que cerca de $33,3 \%$ apresentaram pertinência total ao mesmo. Em seguida, tem-se o perfil 2 , de escolas de médio/grande porte, com equipamentos e instalações básicas, não informatizadas, de nível fundamental - predominante para $16 \%$ das escolas e majoritariamente predominante em um quarto $(24,7 \%)$ delas, tendo ainda uma pertinência total de $7,1 \%$. O perfil 3 , que reúne as grandes escolas urbanas, bem equipadas, com boas instalações, informatizadas, de ensinos médio e fundamental, apresentou uma predominância geral de $9,6 \%$, sendo majoritariamente predominante em 14,7\% e apenas $5,1 \%$ de pertinência total.

A distribuição territorial dos perfis escolares traz importantes informações que permitem maior aprofundamento na investigação de suas características. São apresentados recortes por grandes regiões do país, Estados, porte do município onde se situam, localização da escola em área urbana ou rural e, finalmente, a distribuição segundo os 5.507 municípios existentes no país, em 2000. A ênfase dada concentra-se no percentual de escolas nos perfis extremos em cada unidade investigada, tendo em vista que o foco do trabalho compreende a escola e suas condições de infra-estrutura.

A Tabela 2 mostra a distribuição dos perfis extremos e mistos dentro de cada região do Brasil. O Norte apresenta cerca de $72,3 \%$ de suas escolas classificadas de forma predominante no perfil de baixa infraestrutura. Somando-se os perfis mistos, verifica-se que este perfil foi majoritário para cerca de $78 \%$ das escolas dessa região. No Nordeste, este perfil foi predominante para $61,4 \%$ das escolas e majoritário para aproximadamente $70 \%$. Já na Região Sudeste, tal perfil foi predominante para cerca de $27 \%$ das escolas e majoritário para aproximadamente $40 \%$ delas. No tocante ao perfil de alto nível de infra-estrutura, os maiores percentuais foram encontrados no Sudeste, onde cerca de $20 \%$ das escolas apresentam esse perfil como predominante, contra valores em torno de $4 \%$ nas Regióes Norte e Nordeste. 
GRÁFICO 1

Escolas classificadas no perfil de baixa infra-estrutura Unidades da Federação - 2000

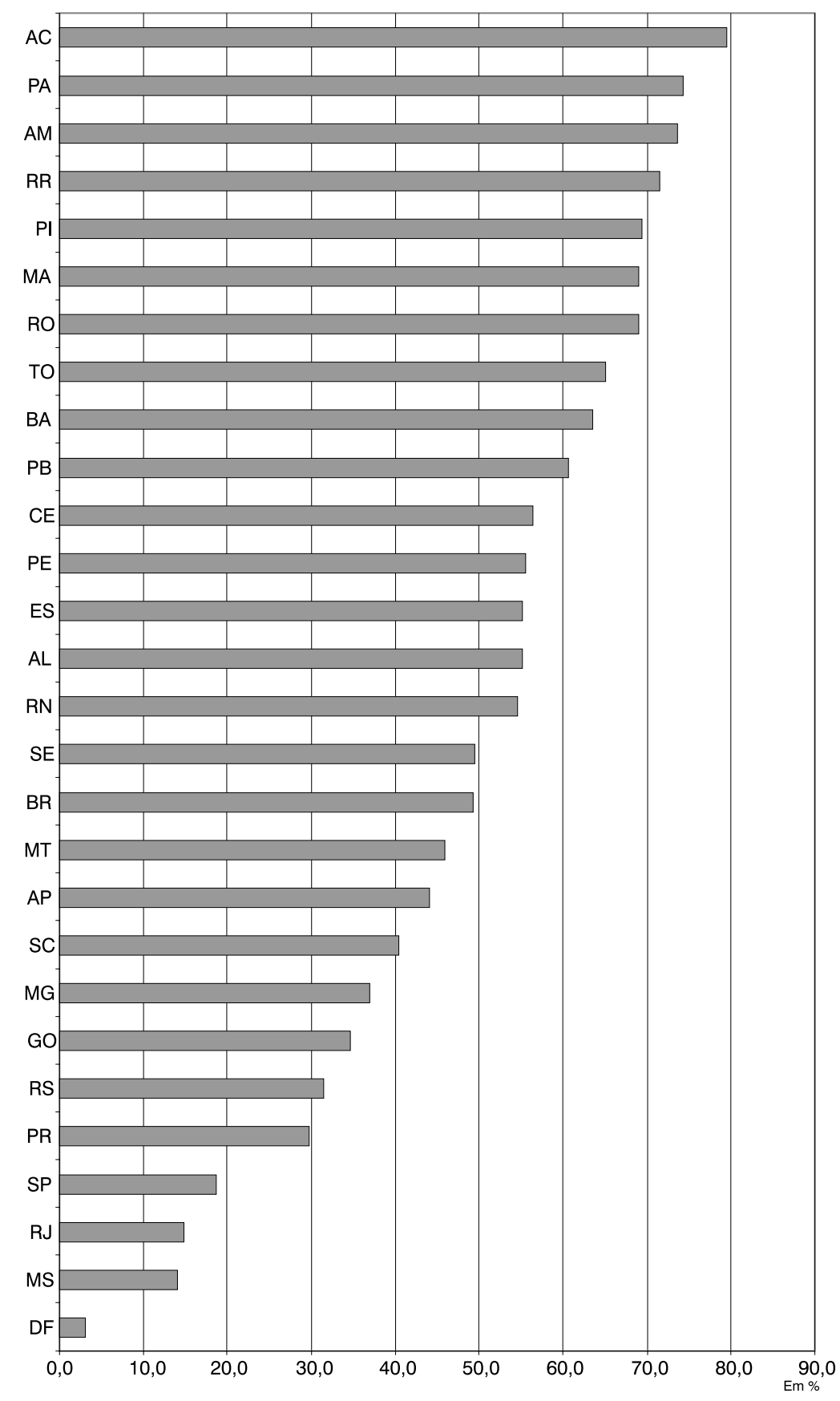

Fonte: Instituto Nacional de Estudos e Pesquisas Educacionais Anísio Teixeira - Inep. Elaboração própria. 
TABELA 2

Distribuição dos estabelecimentos escolares, segundo perfis

Regiões do Brasil - 2000

\begin{tabular}{lrrrrr}
\hline Perfil & Norte & Nordeste & Sudeste & Sul & Centro-Oeste \\
\hline Baixa infra-estr. & 72,3 & 61,4 & 27,2 & 33,2 & 32,5 \\
Baixa+média & 5,3 & 7,9 & 7,9 & 10,0 & 5,2 \\
Baixa+alta & 0,5 & 0,3 & 4,2 & 1,4 & 1,2 \\
Subtotal & $\mathbf{7 8 , 1}$ & $\mathbf{6 9 , 7}$ & $\mathbf{3 9 , 3}$ & $\mathbf{4 4 , 7}$ & $\mathbf{3 8 , 9}$ \\
Média infra-estr. & 9,4 & 15,8 & 15,1 & 21,9 & 23,2 \\
Média+baixa & 3,1 & 5,5 & 2,5 & 3,1 & 3,5 \\
Média+alta & 2,4 & 2,5 & 7,6 & $\mathbf{6 , 8}$ & $\mathbf{8 , 4}$ \\
Subtotal & $\mathbf{1 4 , 9}$ & $\mathbf{2 3 , 9}$ & $\mathbf{2 5 , 2}$ & $\mathbf{3 1 , 8}$ & $\mathbf{3 5 , 0}$ \\
Alta infra-estr. & 4,0 & 3,7 & 19,8 & 13,3 & 16,5 \\
Alta+baixa & 0,7 & 0,6 & 3,5 & 2,1 & 1,7 \\
Alta+média & 1,3 & 1,4 & 7,3 & $\mathbf{4 , 4}$ & 5,7 \\
Subtotal & $\mathbf{6 , 0}$ & $\mathbf{5 , 7}$ & $\mathbf{3 0 , 6}$ & $\mathbf{1 9 , 8}$ & $\mathbf{2 4 , 0}$ \\
Não determinado & 1,0 & 0,7 & 4,9 & $\mathbf{3 , 8}$ & 2,1 \\
Total & $\mathbf{1 0 0 , 0}$ & $\mathbf{1 0 0 , 0}$ & $\mathbf{1 0 0 , 0}$ & $\mathbf{1 0 0 , 0}$ & $\mathbf{1 0 0 , 0}$ \\
\hline
\end{tabular}

Fonte: Instituto Nacional de Estudos e Pesquisas Educacionais Anísio Teixeira - Inep. .Elaboração própria.

GRÁFICO 2

Distribuição dos estabelecimentos escolares, por classes de população residente, segundo os perfis de escolas Brasil-2000

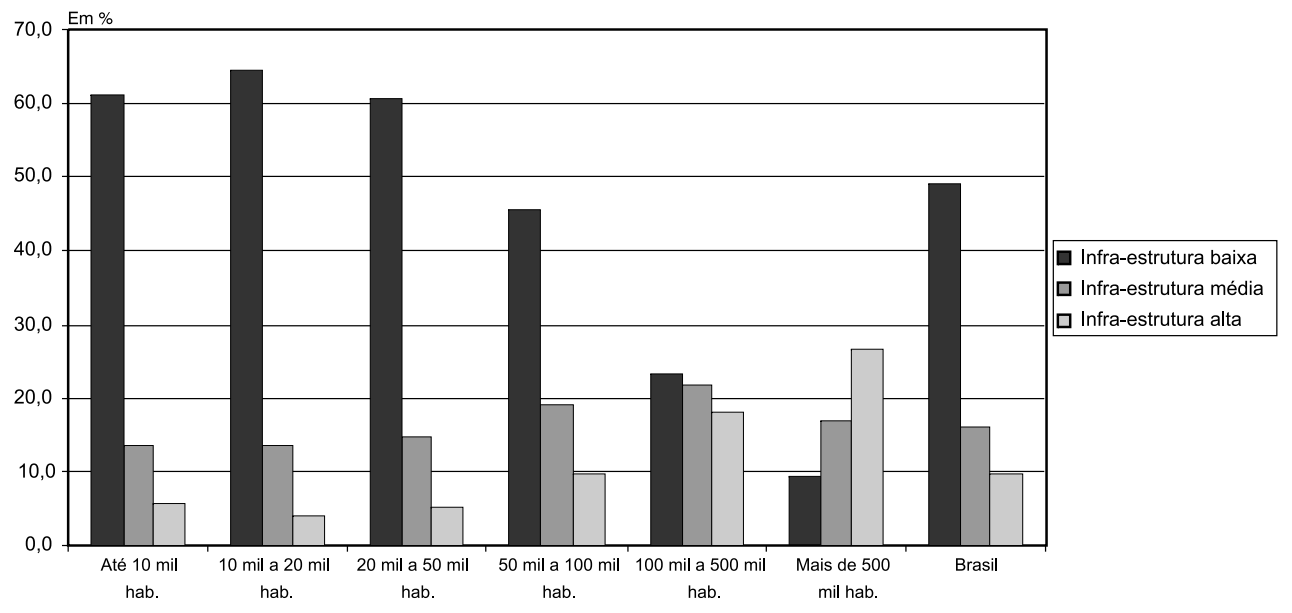

Fonte: Instituto Nacional de Estudos e Pesquisas Educacionais Anísio Teixeira - Inep. Elaboração própria.

A distribuição por unidades da Federação permite uma visão mais detalhada desse quadro de desigualdades, já vislumbrado no exame dos dados das regiões. Assim, verifica-se que Estados como Acre, Pará, Amazonas e Roraima, todos localizados na Região Norte, apresentam mais de $70 \%$ de suas escolas classificadas no perfil de baixa infra-estrutura, ao passo que em São Paulo, Rio de Janeiro, Mato Grosso do Sul e Distrito Federal tais percentuais não atingem $20 \%$ das escolas (Gráfico 1 ).

Um outro recorte territorial importante é o que examina a distribuição dos perfis escolares gerados, segundo o porte dos municípios, em termos de categorias de população residente em 2000 . Os resultados são apresentados no Gráfico 2. 
Os resultados indicam uma associação entre o porte do município onde a escola se localiza e os perfis gerados. Entre os municípios menores (até 10 mil habitantes), por exemplo, o percentual de escolas classificadas no perfil de baixa infra-estrutura é da ordem de $61 \%$, passando para $64,6 \%$ naqueles com 10 mil a 20 mil habitantes e diminuindo a partir daí, até atingir 9,4\% entre os de maior porte (mais de 500 mil habitantes). No perfil de mais elevada infra-estrutura, observa-se situação inversa, embora com percentuais de menor magnitude, que variam de $5,6 \%$ para escolas localizadas em municípios de até 10 mil habitantes, 3,9\% para aquelas situadas em municípios entre 10 mil e 20 mil habitantes, com tendência crescente, chegando a $26,5 \%$ no grupo daqueles com mais de 500 mil habitantes.

A questão da localização da escola em área urbana ou rural também assume importância fundamental na investigação de aspectos territoriais, dada a grande participação de escolas rurais no país e ainda em virtude de suas características peculiares de escolas com indicadores bastante desfavoráveis e com precárias ou inexistentes condições de infra-estrutura. A Tabela 3 mostra a distribuição dos estabelecimentos escolares brasileiros segundo sua localização.

Entre as escolas urbanas, há predominância do perfil intermediário de infra- estrutura (25,5\%), seguido pelo de alta infraestrutura $(20,5 \%)$, ao contrário das rurais, que possuem, em sua maioria (quase $80 \%$ ), baixa infra-estrutura. No que se refere à população atendida, entre as escolas urbanas, cerca de $53 \%$ dos alunos matriculados estudam em estabelecimentos de alta infraestrutura, enquanto na área rural apenas 3,3\% têm acesso a esse tipo de escola. Considerando o perfil de baixa infra-estrutura, verifica-se que menos de $1 \%$ dos alunos das áreas urbanas estudam em tais escolas, ao contrário das rurais, onde este percentual alcança cerca de $45 \%$ dos alunos, salientando a importância e a magnitude desse grupo de escolas tão carentes e que se tornam alvos potenciais de futuras políticas públicas na área da educação.

O exame da distribuição de escolas segundo os perfis gerados, em cada um dos 5.507 municípios brasileiros, em 2000, complementa a investigação do padrão territorial desses perfis, fornecendo uma visão espacializada, de fundamental importância para o aprofundamento do conhecimento das condições de porte e infraestrutura dos estabelecimentos escolares do país. Tais resultados podem ser visualizados nos Mapas 1 a 3, que apresentam os percentuais de escolas em cada um dos perfis extremos, classificados por quartis. Observa-se que municípios com percentuais mais elevados de escolas de baixa

TABELA 3

Estabelecimentos escolares, por localização, segundo perfil gerado Brasil-2000

\begin{tabular}{|c|c|c|c|c|c|c|}
\hline \multirow{3}{*}{ Perfil } & \multicolumn{6}{|c|}{ Localização } \\
\hline & \multicolumn{2}{|c|}{ Urbana } & \multicolumn{2}{|c|}{ Rural } & \multicolumn{2}{|l|}{ Total } \\
\hline & $\mathbf{N}^{\text {os }}$ absolutos & $\%$ & $\mathbf{N}^{\text {os }}$ absolutos & $\%$ & $\mathbf{N}^{\text {os }}$ absolutos & $\%$ \\
\hline Não determinado & 4.715 & 4,7 & 233 & 0,2 & 4.948 & 2,3 \\
\hline Infra-estrutura baixa & 13.931 & 13,9 & 92.940 & 79,3 & 106.871 & 49,2 \\
\hline Infra-estrutura baixa/média & 7.453 & 7,4 & 9.337 & 8,0 & 16.790 & 7,7 \\
\hline Infra-estrutura baixa/alta & 3.138 & 3,1 & 126 & 0,1 & 3.264 & 1,5 \\
\hline Infra-estrutura média & 25.528 & 25,5 & 9.163 & 7,8 & 34.691 & 16,0 \\
\hline Infra-estrutura média/baixa & 4.655 & 4,6 & 4.180 & 3,6 & 8.835 & 4,1 \\
\hline Infra-estrutura média/alta & 9.575 & 9,6 & 497 & 0,4 & 10.072 & 4,6 \\
\hline Infra-estrutura alta & 20.548 & 20,5 & 409 & 0,3 & 20.957 & 9,6 \\
\hline Infra-estrutura alta/baixa & 3.394 & 3,4 & 91 & 0,1 & 3.485 & 1,6 \\
\hline Infra-estrutura alta/média & 7.311 & 7,3 & 188 & 0,2 & 7.499 & 3,4 \\
\hline Total & 100.248 & 100,0 & 117.164 & 100,0 & 217.412 & 100,0 \\
\hline
\end{tabular}

Fonte: Instituto Nacional de Estudos e Pesquisas Educacionais Anísio Teixeira - Inep. Elaboração própria. 
infra-estrutura tendem a se concentrar de forma mais acentuada nas Regiões Norte, Nordeste, norte de Minas e parte do Centro-
Oeste, ao passo que municípios com menores proporções de escolas nesse perfil tendem a se localizar, com mais intensida-

MAPA 1

Distribuição das escolas com perfil de baixa infra-estrutura 2000

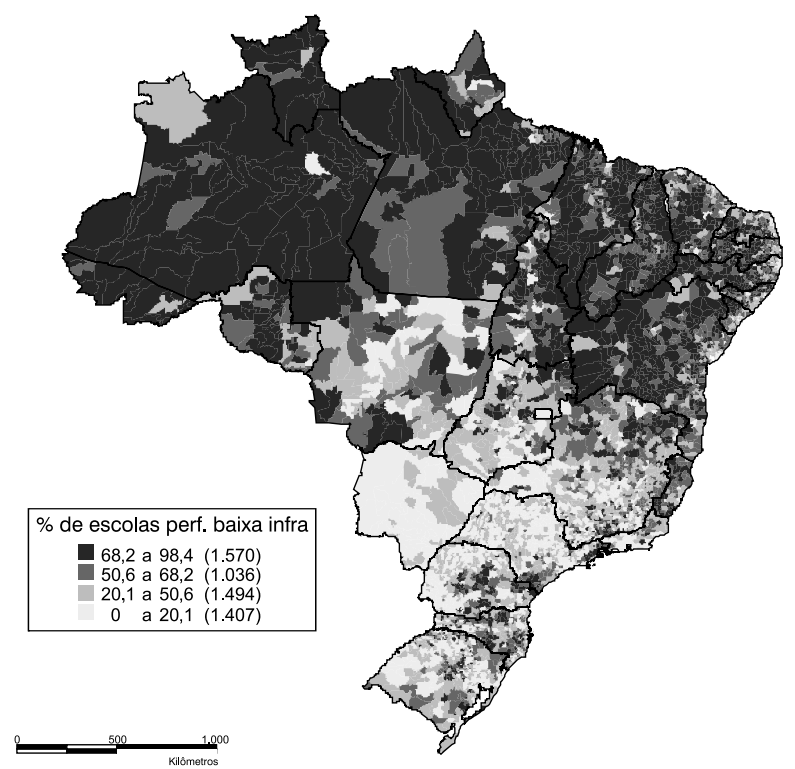

Fonte: Instituto Nacional de Estudos e Pesquisas Educacionais Anísio Teixeira - Inep. Elaboração própria.

MAPA 2

Distribuição das escolas com perfil de média infra-estrutura 2000

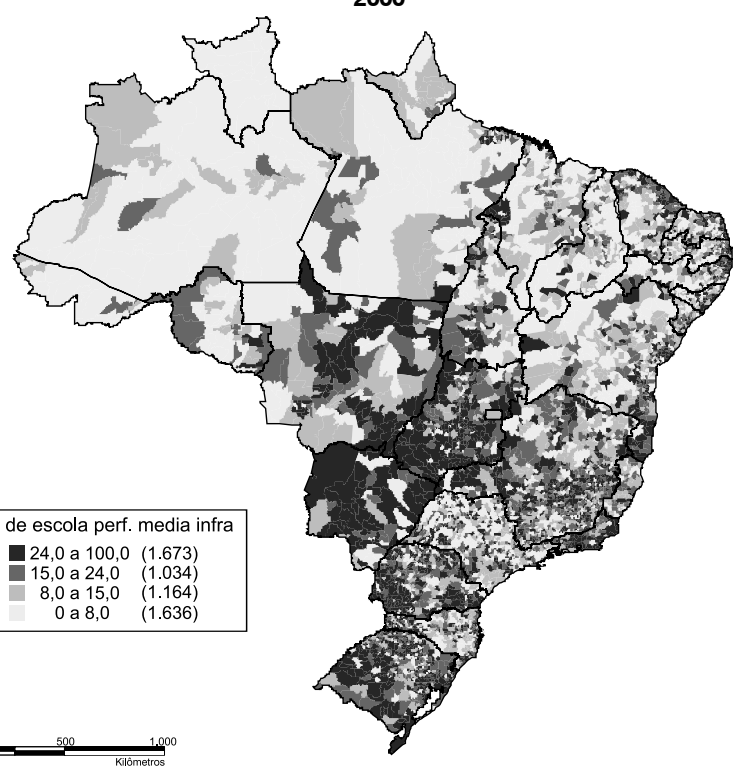

Fonte: Instituto Nacional de Estudos e Pesquisas Educacionais Anísio Teixeira - Inep. Elaboração própria. 


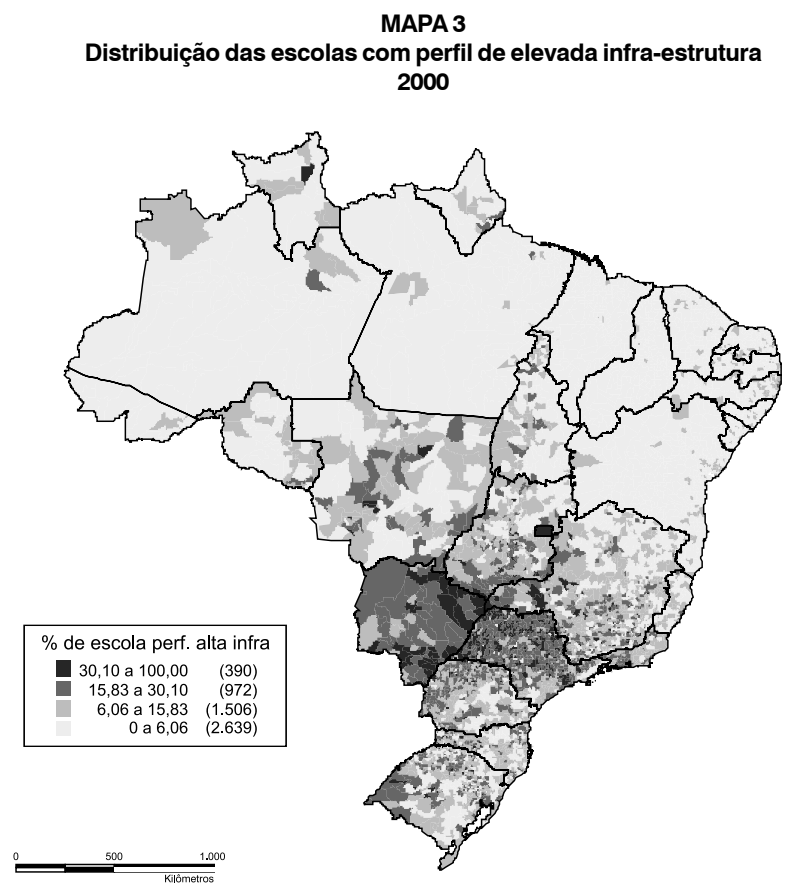

Fonte: Instituto Nacional de Estudos e Pesquisas Educacionais Anísio Teixeira - Inep. Elaboração própria.

de, nas Regiões Sul, Sudeste e Centro-Oeste (Mapa 1). Municípios com elevados percentuais de escolas de condições intermediárias de infra-estrutura (perfil 2) são observados com maior freqüência nas Regiões Centro-Oeste e Sul (Mapa 2), enquanto aqueles com proporções superiores de escolas de maior porte e elevadas condições de infra-estrutura encontram-se, principalmente, nas Regiões Centro-Oeste e Sudeste (Mapa 3).

A investigação da distribuição espacial dos perfis delineados revela a desigualdade na distribuição dos recursos escolares no país. O cruzamento de tais perfis com algumas informações relativas à infra-estrutura escolar apenas corrobora esse quadro.

Escolas com perfis de média/alta e predominantemente alta infra-estrutura destacam-se daquelas pertencentes aos demais perfis quanto a diversos aspectos investigados. A existência de biblioteca, por exemplo, chega a cerca de $90 \%$ no perfil de alta infra-estrutura, enquanto naquele predominantemente de baixa infra-estrutura este valor é praticamente nulo ou muito baixo. Instalações como sala de professores alcançam percentuais acima de $70 \%$ nas escolas de média/alta e predominantemente alta infra-estrutura, atingindo pouco menos de $50 \%$ no perfil de média, quase $40 \%$ no misto de baixa e alta e em torno de $10 \%$ ou menos nos demais de predominância de baixa infra-estrutura.

A presença de equipamentos de informática também é visivelmente superior nos perfis de média/alta e predominantemente de alta infra-estrutura, em que mais de $70 \%$ das escolas têm computador, recurso praticamente inexistente nos perfis de baixa e baixa/média infra-estrutura. $O$ acesso à Internet, baixo no total do país, também parece ser um privilégio dos perfis de alta infra-estrutura, com percentuais em torno de $40 \%$ no de alta infra-estrutura e cerca de $30 \%$ nos mistos de alta/baixa e alta/média infra-estrutura.

A distribuição regional dos perfis, seja de alta ou de baixa infra-estrutura, revela um padrão espacial de desigualdades 
regionais nos aspectos investigados de infra-estrutura educacional, exibindo um quadro nitidamente desfavorável nas Regiões Norte e Nordeste do país.

Em seguida, investigam-se a questão da eficácia escolar e sua distribuição segundo os perfis gerados.

\section{Perfis de eficácia escolar}

Nesta seção, procura-se investigar possíveis associações entre os perfis de escolas gerados anteriormente e alguns indicadores de eficácia escolar, representados pelas taxas de distorção idade-série, de aprovação, de reprovação e de abandono, tanto no ensino fundamental como no médio.

As ferramentas teóricas que permitem a presente análise foram apresentadas na seção metodológica e tratam da estimação das probabilidades $\lambda_{\mathrm{kj} * \mathrm{l}}$ de uma escola pertencente ao perfil " $k$ " apresentar a resposta "l" para a variável "j*” pertencente ao conjunto das variáveis que representam a eficácia escolar - as chamadas variáveis "externas". Convém ressaltar que tais variáveis não foram utilizadas na construção dos perfis multidimensionais escolares, de modo que neste estágio os perfis foram préfixados e os parâmetros de eficácia re-estimados, de tal forma que as novas probabilidades estimadas procuram indicar a associação entre estas variáveis e os perfis extremos anteriormente gerados. De forma semelhante ao que foi feito no caso da construção dos perfis escolares, será utilizada como medida de tal associação a relação entre os $\lambda_{\mathrm{kj}^{*} \mathrm{l}}$ estimados e a freqüência marginal de cada categoria das variáveis externas, tomando-se como referência também o valor de 1,2.

Os principais resultados encontrados no delineamento dos perfis são descritos a seguir.

\section{Perfil 1 - Escolas de baixa infra-estrutura}

Em termos de variáveis de eficácia escolar, este perfil caracteriza-se, no tocante ao ensino fundamental, por altas taxas de distorção, níveis mais elevados de reprovação e mais baixos de aprovação, ao lado de patamares mais elevados de taxas de abandono escolar. Como esse é um perfil caracterizado por escolas de ensino fundamental, são nulos os valores correspondentes ao ensino médio.

\section{Perfil 2 - Escolas de nível intermediário de} infra-estrutura

A eficácia escolar neste perfil, também constituído por escolas de nível fundamental, caracteriza-se predominantemente por baixas taxas de distorção, níveis intermediários de aprovação e reprovação e mais baixos de abandono escolar.

\section{Perfil 3 - Escolas de alta infra-estrutura}

Esse perfil destaca-se como o de melhor situação em termos de eficácia escolar, apresentando, para o ensino fundamental, taxas mais baixas de distorção, níveis mais elevados de aprovação, baixa reprovação, juntamente com patamares menores de abandono escolar. No tocante ao ensino médio, não foi possível detectar alguma associação, tendo em vista a distribuição bastante uniforme das probabilidades condicionais estimadas, o que, combinado com as baixas freqüências marginais, acarreta fatores elevados para todas as categorias investigadas.

\section{Concluindo}

As mudanças demográficas observadas, nas últimas décadas, tiveram impacto no sistema educacional brasileiro, principalmente no tocante à demanda por ensino fundamental, no qual o grau de cobertura já beira a universalização. Entretanto, as classes menos favorecidas da população apresentam dificuldades no acesso a um ensino de qualidade, além de outros desafios urgentes a serem enfrentados, entre os quais a redução dos níveis de repetência e abandono.

O processo de construção da tipologia dos estabelecimentos escolares brasileiros, desenvolvido nesse trabalho, encontrou três perfis de escolas com características distintas. O perfil 1 reuniu, de modo geral, escolas pequenas, rurais, predominante- 
mente municipais, sem as mínimas condições de infra-estrutura e com indicadores educacionais de eficácia escolar deficientes. O perfil 3 englobou escolas, em geral, de grande porte, com excelentes condições de infra-estrutura, elevados níveis de informatização e bons indicadores de eficácia escolar. O perfil 2 tem como característica marcante o fato de reunir escolas em uma situação considerada intermediária quanto aos aspectos de infra-estrutura disponível, porte e funcionais, sendo ainda não informatizadas e com indicadores intermediários de eficácia escolar.

A distribuição das escolas segundo os perfis gerados vem revelar faces de um sistema escolar permeado por grandes lacunas a serem preenchidas. Aproximadamente metade das escolas do país teve como predominante o perfil 1, que, conforme mencionado, tem como característica marcante o fato de reunir estabelecimentos extremamente carentes em termos de infraestrutura e com indicadores de eficácia bastante desfavoráveis. Entretanto, esse perfil congrega apenas cerca de $7 \%$ dos alunos do país, pois se trata, em sua maioria, de escolas de pequeno porte. Quando desagregados por localização, verifica-se que, nas áreas rurais, a maior parte dos alunos estudam em escolas desse perfil de baixa infra-estrutura (45\%), valor que atinge níveis inferiores a $1 \%$ nas áreas urbanas. Já o perfil de escolas de boas condições de infra-estrutura e com indicadores de eficácia favoráveis congregou apenas aproximadamente $10 \%$ das escolas do país e cerca de $58 \%$ dos alunos matriculados. No entanto, nas áreas rurais, é bastante baixo o percentual de alunos que estudam nessas escolas de alta infra-estrutura: $3,3 \%$, contra valores da ordem de $53 \%$ nas áreas urbanas.

A investigação da distribuição espacial dos perfis gerados revelou, entre outros fatos, que cerca de $72 \%$ das escolas da Região Norte e $61,4 \%$ do Nordeste pertencem ao perfil de baixa infra-estrutura, valores bem mais elevados que os $27,2 \%$ e $33,2 \%$ encontrados para as Regiões Sudeste e Sul, respectivamente.

Entre as unidades da federação, o Distrito Federal apresentou tanto o maior percentual de escolas de elevada infraestrutura quanto o menor daquelas de baixa infra-estrutura. Cabe destacar ainda Mato Grosso do Sul, Rio de Janeiro e São Paulo, que estavam entre os Estados com menores percentuais de escolas de baixa infra-estrutura, e o Acre, Pará, Amazonas e Roraima, que, por sua vez, registraram as maiores proporções de escolas nesse último perfil. A distribuição municipal dos perfis de alta ou de baixa infra-estrutura só vem corroborar tais achados, ao revelar um padrão espacial em que se salientam as fragilidades encontradas nas Regiões Norte e Nordeste, ao contrário do que se observa principalmente no Sul e Sudeste do país.

A investigação dos indicadores de eficácia escolar complementa esse quadro de desigualdades entre os perfis, revelando diferenças estatisticamente significativas entre os perfis extremos quanto aos indicadores selecionados. O perfil de baixa infra-estrutura está associado a elevados níveis de distorção idade-série, altos níveis de reprovação e abandono no ensino fundamental, ao contrário do perfil de elevada infra-estrutura.

Os resultados apresentados com o exame das características de cada perfil extremo ou misto agregam novos tons ao quadro delineado. Foram encontradas importantes associações entre a distribuição dos perfis e aspectos tais como porte das escolas, instalações existentes, equipamentos disponíveis e, em particular, o nível de informatização atingido pelas escolas, sempre colocando os perfis em uma espécie de hierarquia, desfavorável ao perfil 1 e situando no outro extremo as escolas de condições, se não ideais, mas ao menos favoráveis nesse quadro traçado.

Desse modo, o processo de construção dos perfis dos estabelecimentos escolares brasileiros também trouxe à tona a fragilidade do sistema educacional, a precariedade em termos de instalações e equipamentos, além de uma série de outras questões fundamentais, entre as quais as marcantes desigualdades, principalmente regionais, quanto aos aspectos investigados.

De posse desse quadro revelado pela tipologia dos estabelecimentos escolares 
brasileiros, mesmo ciente de sua natureza incompleta, espera-se que importantes informações e achados tenham sido revelados e que possam contribuir no aprofundamento do conhecimento da realidade do sistema escolar do país.

Algumas possibilidades de estudos futuros podem ser vislumbradas, como, por exemplo, a investigação do rendimento escolar, segundo as tipologias geradas, que forneceria uma visão de fatores associados ao rendimento escolar e seu comportamento entre escolas de diferentes perfis.

\section{Referências bibliográficas}

ALBERNAZ, A.; FERREIRA, F. H.G.; FRANCO, C. A escola importa? Determinantes da eficiência e equidade no ensino fundamental brasileiro. Maio, 2002. Mimeografado.

ARMOR, D. J. School and family effects on black and white achievment: a reexamination of the USOE data. In: MOYNIHAN, D. P. (Ed.). On equality of educations opportunity: papers deriving from the Harvard University Faculty Seminar on the Coleman Report. New York: Vintage Books, 1972, p.168-229.

BARBOSA, L. D. M. Perfis de vulnerabilidade ao risco de contrair o HIV nas Regiões Nordeste e Sudeste brasileiras: aspectos individuais e da comunidade. Tese de Doutorado. Centro de Desenvolvimento e Planejamento Regional, Universidade Federal de Minas Gerais, 2001. 158 p.

BARBOSA, M. L. Efeitos da qualidade da escola sobre o desempenho dos alunos. Setembro, 2001. Mimeografado.

BARBOSA, M. L. O.; VEIGA, L. Eficiência e equidade: os impasses de uma política. Revista Brasileira de Política e Administração da Educação, v.12, n.2, julho/ dezembro, p.211-242, 1998.

BARROS, R. P.; MENDONÇA, R.S.P.; SHOPE, $J . A$. Regional disparities in education within Brazil: the role of quality of education. Ipea, agosto 1993, p. 1-9. (Textos para discussão, 311).

BARROS, R. P. et alii. Determinantes do desempenho educacional no Brasil. Ipea,
Uma outra possibilidade poderia ser a construção de tipologias em níveis de abrangência geográfica mais específicos, como regional, estadual ou até mesmo municipal. Estes estudos podem ser de grande utilidade no delineamento de metas de melhoria na infra-estrutura das escolas em diferentes níveis de abrangência geográfica. $O$ aprofundamento dos perfis mistos, de maior complexidade por sua natureza, e suas características também poderia ser uma outra linha de investigação derivada desse trabalho.

outubro 2001, p.1-33 (Textos para discussão, 834).

BERKMAN, L.; SINGER, B.; MANTON, K. Black and white differences in health status and mortlity among the elderly. Demography, v.26, November 1989.

BIRDSALL, N.; BRUNS, B.; SABOT, R.H. Education in Brazil: playing a bad hand badly. In: BIRDSALL, N.; SABOT, R.H. (Ed.). Oportunity forgone: education in Brazil. Inter-American Development Bank, 1996, p.7-47.

BUCHMANN, C.; HANNUM, E. Education and stratification in developing countries: a review of theories and research. Rev. Sociol., v.27, p.77-102, 2001.

CALDWELL, J. C. Education as a factor in mortality decline: an examination of Nigerian data. Population studies, v.33, p.395-413, 1979.

CARD, D. A. K.; ALAN, B. School recources and student outcomes: an overview of the literature and new evidence from North and South Carolina. Journal of Economic Perpectives, v.10, n.4, p.31-50, Fall 1996.

CARVALHO, J. A. M. Crescimento populacional e estrutura demográfica no Brasil. Belo Horizonte, 1992.

CARVALHO, J. A. M.; WONG, L. A window of opportunity: some demographic and socioeconomic implications of the rapid fertility decline in Brazil. Universidade 
Federal de Minas Gerais, outubro 1995 (Texto para discussão, 91).

CARVALHO, J. A. M.; SAWYER, D.O.; RODRIGUES, R.N. Introdução a alguns conceitos básicos e medidas em demografia. Belo Horizonte: Abep, 1998. 63 p. (Textos didáticos).

CASTRO, M. H. G.; DAVANZO, A. M. Q. Situação da educação básica no Brasil. Brasília: Inep, 1999. 134 p.

CERQUEIRA, C. A. Uma tipologia dos municípios da região Nordeste. Belo Horizonte, 2002. Mimeografado.

CHRISTENSON, B. A.; JOHNSON, N.E. Educational inequality in adult mortality: an assesment with death certificate data from Michigan. Demography, v.32, n.2, May, 1995, p.215-229, 1995.

COLEMAN, S. Equality of educational opportunity. Office of Education, U.S. Washington D.C. 1966.

DAVIDSON, J. et alii. A study of depressive typologies using grade of membership analysis. Psychol Med. v.18(1), p.179-189, 1988.

EBOLI, M. G. L'éteregeneità dell'agrocoltura: chave classificatorie e interpretative nella letteratura economico-agraria. Agricoltura familiare in transizione, v.s1, p.75-91, 1995.

FLETCHER, P. R.; RIBEIRO, S.C. O ensino de primeiro grau no Brasil hoje. Inep, 1987.

FULLER, B.; CLARK, P. Raising school effects while ignoring culture? Local conditions and the influence of classroom tools, rules and pedagogy. Review of Educational Research, v.64, n.1, p.119157, 1994.

GARCIA, R. A. Modernização e crescimento populacional nos municípios de Minas Gerais: uma aplicação do método "Grade of Membership". In: SEMINÁRIO SOBRE A ECONOMIA MINEIRA, IX. Diamantina: Cedeplar/UFMG, 2000.

HANUSHEK, E. A. Interpreting recent research on schooling in developing countries. The World Bank Research
Observer, v.10, n.2, August, p.227-246, 1995.

IBGE. Perfil dos municípios brasileiros. Rio de Janeiro: IBGE, 2001.

INSTITUTO NACIONAL DE ESTUDOS E PESQUISAS EDUCACIONAIS. Sinopse da educação básica no Brasil. Disponível em: $<$ http://www.inep.gov.br>. Acesso em: out./ 2003.

Geografia da educação brasileira 2001. Brasília: Inep, 2002.

KAGEYAMA, A.; LEONE, E.T. Uma tipologia dos municípios paulistas com base em indicadores sociodemográficos. Campinas, IE/Unicamp, 1999 (Textos para discussão, 66).

KLEIN, R.; RIBEIRO, S. C. O Censo Educacional e o modelo de fluxo: o problema da repetência. Revista Brasileira de Estatística, v.52, n.197, p. 5-45,1991.

LEME, M.; WAJNMAN, S. A alocação de tempo dos adolescentes brasileiros entre o trabalho e a escola. Ouro Preto-MG: Associação Brasileira de Estudos Populacionais, 2000.

MANTON, K. G.; VERTREES, J.C. The use of grade of membership analysis to evaluate and modify diagnosis-related groups. J.C. Medical care, v. 22(12), p.1067-1082, 1984.

MANTON, K. G.; WOODBURY, M.A.; TOLLEY, H.D. Statistical applications using fuzzy sets. New York: John Wiley, 1994. 312 p.

MARTELETO, L. Desigualdade regional e intergeracional de oportunidades: a matrícula e a escolaridade de crianças e jovens no Brasil. In: ENCONTRO DA ASSOCIAÇÃO BRASILEIRA DE ESTUDOS POPULACIONAIS, XIII. Ouro Preto-MG, 2002. Anais... Abep, 2002. Disponível em CD-ROM.

MELLO, G. N. Escolas eficazes: um tema revisitado. In: IPEA (Ed.). Gestão escolar: desafios e tendências. Brasília, 1994 (Série Ipea, 145).

NAÇÕES UNIDAS. Panorama social de América Latina: 2001-2002. Santiago de 
Chile: Naciones Unidas/Cepal, 2002. $272 \mathrm{p}$.

PNUD - Programa das Nações Unidas para o Desenvolvimento. Relatório do Desenvolvimento Humano - 2002. Portugal: PNUD, 2002. 277 p.

SAWYER, D. et alii. Caracterização dos tipos de doadores de sangue em Belo Horizonte: heterogeneidade do homogêneo. In: ENCONTRO NACIONAL DE ESTUDOS POPULACIONAIS, X. CaxambuMG, 2000. Anais... Abep, 2000. Disponível em CD-ROM.
SCHWARTZMAN, S. The challlenges of education in Brazil. University of Oxford Centre for Brazilian Studies, Jan.-Mar. 2003. (Working paper series, v.CBS 38/2003). Disponível em: <http://www.schwartzman. org.br/simon/publicac.htm> p.1-40, 2003.

WILLMS, J. D.; SOMERS, M.A. Schooling outcomes in Latin America. Unesco, agosto, 1999, p.1-43.

WILLMS, J. D. Monitoring school performance for "standards-based reform". Evaluation and Research in Education, v.14, June, p.237253, 2000.

\section{Resumen}

Tipología de los establecimientos escolares brasileños

La propuesta central del trabajo es la construcción de una tipología para los establecimientos escolares brasileños, a partir de un amplio conjunto de informaciones que comprenden la infraestructura ofrecida por los mismos, su porte, indicadores de calidad de la enseñanza ofrecida, entre otros aspectos. La construcción de la tipología se cristaliza en el delineamento de perfiles extremos de escuelas, en verdad grupos con características distintivas. Otra dimensión investigada fue la eficacia escolar, teniendo como principal interés verificar su distribución según los perfiles anteriormente generados. La tipología de las escuelas reveló tres perfiles extremos: uno de escuelas con precarias condiciones de infraestructura e indicadores deficientes de eficacia escolar; otro, en situación opuesta, con grandes escuelas, con buenas condiciones de infraestructura y buenos indicadores de eficacia; y un tercer perfil, que quedó en una posición de transición entre los dos primeros. Preocupa el hecho que la mayoría de las escuelas brasileñas se encuadran en el perfil de precarias condiciones de infraestructura, cuadro agravado por las disparidades regionales.

Palabras-clave: Educación. Demografía de la educación. Escuelas.

\section{Abstract}

\section{Typology of Brazilian schools}

The main objective of this article is to develop a typology of Brazilian schools using a broad set of information, such as school size, infrastructure, quality of educational offer, and many others. The typology is based on the establishment of extreme profiles of schools, clustering them by similar characteristics. School efficiency was also investigated, in order to observe its distribution according to the extreme profiles. The typology of the schools indicated three extreme profiles. The first profile is of schools with inadequate infrastructure and poor efficiency indicators, the second refers to large schools with high infrastructural level and good efficiency indicators. The third profile is at an intermediate range between the first and second. One cause for concern is that most Brazilian schools are classified in the category of having precarious infrastructures, which are worse in some regions than in others.

Key Words: Education. Educational demography. Schools. 
